\title{
Polymorphism screening and haplotype analysis of the tryptophan hydroxylase gene (TPHI) and association with bipolar affective disorder in Taiwan
}

\author{
Te-Jen Lai ${ }^{1,2}$, Chia-Yen $\mathrm{Wu}^{3}$, Hsu-Wen Tsai ${ }^{4}$, Yi-Mei J Lin ${ }^{5}$ and $\mathrm{H}$ \\ Sunny Sun*3,5
}

\begin{abstract}
Address: ${ }^{1}$ Institute of Medicine, Chung Shan Medical University, Taichung, Taiwan, Republic of China, ${ }^{2}$ Department of Psychiatry, Chung Shan Medical University Hospital, Taichung, Taiwan, Republic of China, ${ }^{3}$ Institute of Molecular Medicine, National Cheng Kung University Medical College, Tainan, Taiwan, Republic of China, ${ }^{4}$ Institute of Behavioral Medicine, National Cheng Kung University Medical College, Tainan, Taiwan, Republic of China and ${ }^{5}$ Institute of Basic Medical Sciences, National Cheng Kung University Medical College, Tainan, Taiwan, Republic of China

Email: Te-Jen Lai - tejenlai@hotmail.com; Chia-Yen Wu - wu5@buffalo.edu; Hsu-Wen Tsai - hwtsai@mail.2000.com.tw; YiMei J Lin - s5889121@ccmail.ncku.edu.tw; H Sunny Sun* - hssun@mail.ncku.edu.tw

* Corresponding author
\end{abstract}

Published: 31 March 2005

BMC Medical Genetics 2005, 6:14 doi:10.1186/147|-2350-6-14
Received: 13 August 2004

Accepted: 31 March 2005

This article is available from: http://www.biomedcentral.com/l47I-2350/6/14

(C) 2005 Lai et al; licensee BioMed Central Ltd.

This is an Open Access article distributed under the terms of the Creative Commons Attribution License (http://creativecommons.org/licenses/by/2.0), which permits unrestricted use, distribution, and reproduction in any medium, provided the original work is properly cited.

\begin{abstract}
Background: Disturbances in serotonin neurotransmission are implicated in the etiology of many psychiatric disorders, including bipolar affective disorder (BPD). The tryptophan hydroxylase gene (TPH), which codes for the enzyme catalyzing the rate-limiting step in serotonin biosynthetic pathway, is one of the leading candidate genes for psychiatric and behavioral disorders. In a preliminary study, we found that $T P H I$ intron7 A2I8C polymorphism was associated with BPD. This study was designed to investigate sequence variants of the TPHI gene in Taiwanese and to test whether the TPHI gene is a susceptibility factor for the BPD.

Methods: Using a systematic approach, we have searched the exons and promoter region of the TPHI gene for sequence variants in Taiwanese Han and have identified five variants, A-I067G, G-347T, T3804A, C27224T, and A27237G. These five variants plus another five taken from the literature and a public database were examined for an association in 108 BPD patients and 103 controls; no association was detected for any of the 10 variants.

Results: Haplotype constructions using these 10 SNPs showed that the 3 most common haplotypes in both patients and controls were identical. One of the fourth common haplotype in the patient group (i.e. GGGAGACCCA) was unique and showed a trend of significance with the disease $(P=0.028)$. However, the significance was abolished after Bonferroni correction thus suggesting the association is weak. In addition, three haplotype-tagged SNPs (htSNPs) were selected to represent all haplotypes with frequencies larger than $2 \%$ in the Taiwanese Han population. The defined TPHI htSNPs significantly reduce the marker number for haplotype analysis thus provides useful information for future association studies in our population.

Conclusion: Results of this study did not support the role of TPHI gene in BPD etiology. As the current studies found the TPHI gene under investigation belongs to the peripheral serotonin system and may link to a cardiac dysfunction phenotype, a second TPH gene that functions predominantly in the brain (i.e., nTPH or TPH2) should be the target for the future association study.
\end{abstract}




\section{Background}

Bipolar affective disorder (BPD) is a chronic, severe mood disorder characterized by recurrent episodes of mania and depression. It often interferes with the patient's ability to cope with his daily routine and has a high mortality rate from suicide. BPD is estimated to have a lifetime prevalence of $0.1 \%$ to $1 \%$ in Taiwanese Han [1]. The high prevalence, together with the high frequency of hospitalization, psychosocial impairment, suicide, and substance abuse has made the disease a major public health concern. Although previous studies in epidemiology strongly suggested genetic factors in the etiology of affective disorder [2], establishing the mode of transmission and searching for predisposing genes using linkage analyses have not been successful. Association studies have been useful in mapping genes for complex diseases and are now being applied to many psychiatric traits [3]. However, the success of this approach requires the markers of the candidate gene being used are either the causative variant(s) or in linkage disequilibrium with the causative variant(s) [4]. Results from these studies suggest the involvement of several genes, each of which has a minor effect on the pathogenesis of BPD [5].

Serotonin (also known as 5-hydroxytryptamine) is a major neurotransmitter in the central nervous system (CNS) and is involved in various physiological events, such as mood control, sleep, thermoregulation, learning, and memory [6]. Its role in psychiatric disorders is well documented [7]. Disruption of serotonergic function has been implicated in the pathogenesis of many psychiatric disorders, including BPD $[8,9]$, making genes involved in serotonin transmission and its metabolic pathway good candidates for involvement in BPD pathogenesis.

Tryptophan hydroxylase (TPH) catalyzes the biopterindependent monooxygenation of tryptophan to 5-hydroxytryptophan, which is subsequently decarboxylated to form the neurotransmitter, serotonin [10]. Two tryptophan hydroxylase isoforms have been identified [1113] and the expression of TPH 1 and TPH 2 were found to be mainly in the pineal gland [14] as well as in the peripheral tissues (duodenum, kidney or lung; [15]) and in the brain stem $[12,15]$, respectively. The TPH1 gene has been the subject of intensive study regarding its possible involvement in many psychiatric and behavioral traits [16]; And an increasing number of investigations have studied the TPH2 gene effect in association with several psychiatric and behavioral traits including antidepressant response [17] and major depression [18].

The TPH1 gene, which has been mapped to human chromosome 11p15.3-p14 [13], spans a region of 29 kilobases and consists of 11 exons [19]. Numerous mRNA species are transcribed from a single promoter by alternative splicing of three exons (1A, 1B, and $1 \mathrm{C})$ in the 5 '- untranslated region (UTR) $[19,20]$ and two exons (11A and 11B) in the 3'UTR $[19,20]$. The structure of the gene and the sequence of the coding region are very similar to those for the genes for human tyrosine hydroxylase and phenylalanine hydroxylase, which belong to the super-family of aromatic amine acid hydroxylases. Polymorphisms within intron 7 of the TPH1 gene have been implicated to be associated with several psychiatric conditions such as BPD [21], suicidal behavior and alcoholism [22], and aggression-related traits [23]. Furthermore, the TPH1 intron 7 polymorphism was associated with the 5-HIAA level in both impulsive Finnish alcoholics [24] and healthy men [25] thus suggesting that TPH1 genotypes may participate in the regulation of serotonin turnover rate in the central nervous system. However, such associations were not found in other studies involving suicidal behavior [26], BPD and mood disorders [27,28], and attention-deficit hyperactivity disorder [29]. These studies indicate that the role of TPH1 in predisposing different psychiatric traits varies and could be modified by other factors like ethnicity or gene-to-gene interactions [30]. Preliminary study in our laboratory has found an allelic association $(\mathrm{P}=0.03)$ between the TPH1 intron 7 A218C polymorphism and BPD in 42 Taiwanese bipolar patients and 70 matched healthy controls [31]. Results from these studies suggest that TPH1 may play a role in regulating serotonin metabolism. More recently, sertraline, a selective serotonin reuptake inhibitor and an effective antidepressant, has been shown to up-regulate TPH1 expression and serotonin synthesis [32], suggesting one of the mechanism for its pharmacological action in antidepressive therapy.

To provide information of the TPH1 gene for future genetic analysis of disorders involved the disturbances in the serotonergic system in Taiwan, we have systematically screened all 11 exons and the promoter region of the human TPH1 gene for common sequence polymorphisms and have identified 5 single nucleotide polymorphisms (SNPs). In addition, we carried out a case-control study of 108 BPD type I patients and 103 normal controls looking for an association between BPD and these 5 SNPs plus 5 others taken from the literatures $[33,34]$ and a public SNP database [35], tested both as individual SNPs and as the haplotypes.

\section{Methods Subjects}

Since 1998, probands were recruited from bipolar outpatients in the Chung Shan Medical University Hospital and the Taichung Rehabilitation Hospital in Taiwan. Controls were subjects from local volunteer blood donors who have no family or personal history of major affective disorder and other psychiatric disorders were matched to 
cases on the basis of ethnic or geographic origin, sex, and age. The gender ratios are identical in both case and control groups (male to female is $53 \%$ to $47 \%$ ) and the age of populations are $38 \pm 13.7$ and $26.4 \pm 7.9$ in case and control groups, respectively. The age of onset is $28.4 \pm$ 12.7 in all patients and is $30.3 \pm 14.5$ and $26.4 \pm 10.2$ in male and female patients, respectively. Clinical interviews were conducted by experienced psychiatrists (leading by Dr. Lai) for all subjects after the study procedure had been fully explained and information on general demographic data, such as age, sex, and ethnicity, was obtained. Patients assessment was purely by direct clinical interview by the treating clinician according the procedure described in the DSM-IV diagnoses of lifetime Major depressive disorder and bipolar I. Additional information required to reach diagnosis was also collected from all clinical and hospital records where available but the comorbidity with other psychiatric/neurological disorders or medical problems were not considered as an inclusion/ exclusion criteria. This study was approved by the University Ethics Committee and written informed consent was obtained from all participants. In total, 108 BPD and 103 controls (all Taiwanese Han) were recruited for this study.

\section{DNA preparation}

Approximately $10 \mathrm{ml}$ of peripheral blood was collected from the recruits using EDTA anticoagulant venous blood tubes, and DNA prepared using a BIO-RAD InstaGene ${ }^{\mathrm{TM}}$ Whole Blood Kit (Bio-Rad Laboratory, Hercules, CA) according to the manufacturer's protocol.

\section{Primer design for searching for, and typing of, TPHI gene polymorphisms}

All primers used were designed using the Primer3 program [36] or OLIGO 5 Primer Analysis Software (Molecular Biology Insights, Inc., cascade. CO., USA). The primers used to screen the TPH1 gene (Table 1) were designed using the published sequence (GenBank accession

Table I: Summary of the 10 human TPHI SNPs genotyped in this studya

\begin{tabular}{|c|c|c|c|}
\hline SNP name (Genomic localization) ${ }^{b}$ & Position in the gene & SNP IDc & PCR primers and short-extension probe ${ }^{\mathrm{e}}$ \\
\hline 5'flankingSNPI (T-I72IG) & 5 ' flanking region & SNP00057435I & $\begin{array}{l}\text { F: 5'-ctgttcttttggtgtcctc-3' } \\
\text { R:5'-gctcctggcacttaacata-3' } \\
\text { P: } 5^{\prime} \text {-taatttctttcatgagtattttatagtt }\end{array}$ \\
\hline 5'flankingSNP2 (A-1067G) & 5' flanking region & SNP000574353 & $\begin{array}{l}\text { F: 5'-ctgttcttttggtgtcctc-3' } \\
\text { R: 5'-gctcctggcacttaacata-3' } \\
\text { P: 5'-ttttttgctgagtatggatgtactttaaagctcagga }\end{array}$ \\
\hline 5'flankingSNP3 (G-347T) & 5 ' flanking region & SNP000574354 & $\begin{array}{l}\text { F: 5'-cgataataggcgttatcttg-3' } \\
\text { R: 5'-ctcaatctctgcgtgtatct-3' } \\
\text { P: 5'-tcaggactgggctattaaatagcccagaagcacagaga }\end{array}$ \\
\hline in ISNPI (T3804A) & Intron I (exon Ic) & rs 623580 & $\begin{array}{l}\text { F: 5'-taattatcctccctccaagt-3' } \\
\text { R: 5'-cttacccattcaattaccac-3' } \\
\text { P: 5'-agagtatgggcgacgttgtccta }\end{array}$ \\
\hline in2SNPI (G7465A) & Intron 2 & rs684302 & $\begin{array}{l}\text { F: 5'-tgctcttatatgtcttttcaagt-3' } \\
\text { R: 5'-gagagatggagcaaaacac-3' } \\
\text { P: 5'-ttaaataaaatacctgtatgtcttcttccatca }\end{array}$ \\
\hline in3SNPI (AI25I7C) & Intron 3 & rs2111105 & $\begin{array}{l}\text { F: 5'-tcaggaaaacagaagggta-3' } \\
\text { R: 5'-ggtaaattgccctatttctaa-3' } \\
\text { P: 5'-aggtggcaaagacaaatgatttctaagatcttttccatcggc }\end{array}$ \\
\hline in6SNPI (CI8626G) & Intron 6 & rs2237907 & $\begin{array}{l}\text { F: 5'-gggaagaaattatgtaagtgg-3' } \\
\text { R: 5'-gaaatgttccatatctgtgc-3' } \\
\text { P: 5'-ttgtaatgcacacaaaactgaaagctgatctcttagggtctggagc }\end{array}$ \\
\hline in7SNPI $(A 20004 C)^{d}$ & Intron 7 & rs 1800532 & $\begin{array}{l}\text { CF: 5'-acccacctacactttcctc-3' } \\
\text { CR: 5'-taattgacaacctattaggttc-3' } \\
\text { AR: 5'-agcacatgtgaagcatttag-3' } \\
\text { AF: 5'-cctatgctcagaatagcagctct-3' }\end{array}$ \\
\hline 3'UTRSNPI (C27224T) & 3' UTR & rs2108977 & $\begin{array}{l}\text { F: 5'-cacttgaatatcacagtccatc-3' } \\
\text { R: 5'-gcttacagtagatttccttgc-3' } \\
\text { P: 5'-tacatttgatggtaaatagatgctagctaatct }\end{array}$ \\
\hline 3'UTRSNP2 (A27237G) & 3' UTR & New & $\begin{array}{l}\text { F: 5'-cacttgaatatcacagtccatc-3' } \\
\text { R: 5'-gcttacagtagatttccttgc-3' } \\
\text { P: 5'-aactataaatcagataatcaata }\end{array}$ \\
\hline
\end{tabular}

a. in7SNPI was genotyped using ARMS, while the other SNPs were genotyped using MSBE.

b. Genomic localizations of SNPs are given in bp relative to the transcription start site (position 0 ).

c. The ID for 5'flankingSNPI, 5'flankingSNP2, and 5'flankingSNP3 are from HGVbase http://hgvbase.cgb.ki.se/. The ID for in ISNPI, in2SNPI, in3SNPI, in6SNPI, in7SNPI, 3'UTRSNPI, and 3'UTRSNP2 are from dbSNP http://www.ncbi.nlm.nih.gov/SNPI.

d. The A20004C is known as intron7 A218C polymorphism.

e. All PCR reactions were performed at the same annealing temperature $\left(53^{\circ} \mathrm{C}\right)$. F: forward primer, R: reverse primer, P: short extension probe. 
number: AC005728). The primers used in exon-wide SNP scanning were designed from the intronic sequence roughly 50 bp upstream and downstream of each exon to amplify the entire exon sequences. In addition, overlapping fragments covering from 1,151 bp upstream of the $5^{\prime}$ promoter region to $1,572 \mathrm{bp}$ downstream of the 3 'UTR were also amplified to screen for polymorphisms within these regions. The forward and reverse primers for base excision sequence scanning (BESS) product amplification were labeled, respectively, with fluorescent 6-FAM and HEX to facilitate variant detection.

\section{SNP identification in the coding and regulatory regions of the TPHI gene}

In order to identify all SNPs in the coding and regulatory regions of the TPH1 gene, we designed primers to generate PCR products for use in SNP identification using the BESS Base Reader Kit (Epicentre Technologies, Madison, WI) according to the manufacturer's protocol. Each identified SNP was sequenced to confirm the sequence variant. The screening panel included 50 unrelated subjects with or without BPD.

The BESS T \& G Base Reader Kit, which identifies all types of point mutation, deletion, insertion, repeat expansion, and frameshift mutation at sites involving thymine or guanine, was used to systematically search for sequence variants in pooled samples. DNA sequence variants are detected by cleavage of the amplification products at modified nucleotides, generating a defined series of fragments which can be easily separated on a standard sequencing gel and detected using a fluorescent dye detection system. Briefly, PCR products were generated using FAM-labeled forward primers and HEX-labeled reverse primers. PCR amplification was performed in a $25 \mu \mathrm{l}$ volume containing 1 unit of Taq polymerase, $1 \times$ PCR buffer, $0.2 \mu \mathrm{M}$ of each labeled primer, an appropriate concentration of $\mathrm{MgCl}_{2}, 200 \mu \mathrm{M}$ BESS T/G Scan dNTP Mix, and 50 ng of genomic DNA. Thermal cycling conditions were a pre-denaturation of $3 \mathrm{~min}$ at $94^{\circ} \mathrm{C}$; 35 cycles of $30 \mathrm{sec}$ at $94^{\circ} \mathrm{C}, 30 \mathrm{sec}$ at the appropriate annealing temperature indicated in Table 1 , and 30 sec of extension at $72^{\circ} \mathrm{C}$; and a final extension at $72^{\circ} \mathrm{C}$ for $5 \mathrm{~min}$.

For the excision reaction, $5 \mu \mathrm{l}$ of the amplification reaction was mixed with $1 \mu \mathrm{l}$ of the BESS T/G-Scan Excision Enzyme Mix and $1 \mu$ lof 10X BESS T/G-Scan Excision Enzyme Buffer, the mixture incubated for 30 minutes at $37^{\circ} \mathrm{C}$, and the reaction stopped by adding $5 \mu \mathrm{l}$ of Stop/ Loading Buffer. One microliter of the excision reaction products was mixed with gel loading solution containing $12 \mu \mathrm{l}$ of formamide and $8 \mu \mathrm{l}$ of GENESCAN ${ }^{\mathrm{TM}}$-500 size standards (Applied Biosystems, Forster City, CA, USA), then the mixture was denatured for $5 \mathrm{~min}$ at $95^{\circ} \mathrm{C}$, loaded onto a capillary polymer of the ABI 310 Genetic Analyzer, and run for $30 \mathrm{~min}$ for size separation. Analysis was performed using the GENESCAN 672 program (Applied Biosystems).

To reduce the cost and speed up the process, a pooling methodology was used. A preliminary test indicated that the sensitivity of BESS T/G-Scan analysis allowed the detection of alleles with a frequency in the population greater than $4.5 \%$ (data not shown), i.e., The assay can recognize 1 heterozygous individual in a DNA pool from this individual and 9 homozygotes (equivalent to a minor allele with a frequency of 5\%). DNA from 10 individuals was therefore pooled $(10 \mathrm{ng} / \mu \mathrm{l}$ of DNA from each individual) and five such pools, representing 100 chromosomes, were prepared from 50 randomly selected subjects for polymorphism identification.

\section{Selection of SNP markers for the TPHI gene}

In addition to the SNPs identified in the present study, five SNP markers within and flanking the human TPH1 gene were also selected to test the association with BPD. Based on the literature [34] and a public SNP database [35], SNP markers roughly $10 \mathrm{~kb}$ apart and with a relatively high minor allele frequency were selected. The TPH1 intron 7 A218C polymorphism, which has been suggested to be associated with Taiwanese BPD in our previously work, also has been included in the present study (i.e. in7SNP1; A20004C). The genomic localizations of the 10 SNPs examined relative to the transcription start site are given in Table 1.

\section{SNP genotyping}

Except for the intron 7 A218C polymorphism, which was genotyped using a modified Amplification Refractory Mutation System (ARMS), all other SNPs of the TPH1 gene were genotyped using a multiple SNP genotyping system which involves multiplex PCR and multiple single base extensions (MSBE). Briefly, two multiplex PCR reactions were performed. One was in a $20 \mu \mathrm{l}$ volume containing $70 \mathrm{ng}$ of genomic DNA, $2.4 \mu \mathrm{l}$ of primer mix $(0.1 \mu \mathrm{M}$ of the primer pairs for 5'flankingSNP3, in1SNP1, in2SNP1, and in6SNP1, and $0.2 \mu \mathrm{M}$ of the primer-pair for in3SNP1), $400 \mu \mathrm{M}$ dNTPs, $1 \times$ PCR buffer, $1.5 \mathrm{mM} \mathrm{MgCl}_{2}$, and $1 \mathrm{U}$ of Taq polymerase. The conditions used were an initial denaturation step of $5 \mathrm{~min}$ at $95^{\circ} \mathrm{C}, 30$ cycles of amplification $\left(30 \mathrm{~s}\right.$ at $95^{\circ} \mathrm{C}, 60 \mathrm{~s}$ at $51^{\circ} \mathrm{C}, 90 \mathrm{~s}$ at $\left.72^{\circ} \mathrm{C}\right)$, and a final extension step of $10 \mathrm{~min}$ at $72^{\circ} \mathrm{C}$. The other multiplex PCR was performed under the same conditions, but using $0.8 \mu \mathrm{l}$ of primer mix containing $0.1 \mu \mathrm{M}$ of the primer pairs for 5'flankingSNP1, 5'flankingSNP2, 3'UTRSNP1, and 3'UTRSNP2. A $4 \mu \mathrm{l}$ aliquot of the PCR products was treated with $5 \mathrm{U}$ of shrimp alkaline phosphatase (SAP) and $0.1 \mathrm{U}$ of exonuclease I in a total volume of $10 \mu \mathrm{l}$ to remove primers and unincorporated dNTPs; the reaction was carried out at $37^{\circ} \mathrm{C}$ for 1 hour, 
Table 2: Genotype and allele frequencies of the TPHI gene polymorphisms.

\begin{tabular}{|c|c|c|c|c|c|c|c|c|c|c|}
\hline \multirow[t]{2}{*}{ Marker } & \multirow{2}{*}{$\begin{array}{l}\text { Group }^{\mathrm{a}} \\
\text { (Total Number) }\end{array}$} & \multicolumn{5}{|c|}{ Genotype $^{b}$ (frequency) } & \multicolumn{4}{|c|}{ Allele (frequency) } \\
\hline & & 11 & 12 & 22 & $x^{2}$ & $p$ value & 1 & 2 & $x^{2}$ & $P$ value \\
\hline \multirow[t]{2}{*}{$\mathrm{T}-|72| \mathrm{G}$} & $N(94)$ & $54(.57)$ & $37(.39)$ & $3(.03)$ & 2.79 & 0.248 & $145(.77)$ & $43(.23)$ & 0.36 & 0.548 \\
\hline & $P(92)$ & $53(.58)$ & $31(.34)$ & $8(.09)$ & & & $137(.75)$ & $47(.26)$ & & \\
\hline \multirow[t]{2}{*}{ A-1067G } & $N(90)$ & $53(.59)$ & $34(.38)$ & $3(.03)$ & 1.62 & 0.446 & $140(.78)$ & $40(.22)$ & 0.74 & 0.389 \\
\hline & $\mathrm{P}(92)$ & $51(.55)$ & $34(.37)$ & $7(.08)$ & & & $136(.74)$ & $48(.26)$ & & \\
\hline \multirow{2}{*}{ G-347T } & $N(102)$ & $58(.57)$ & $43(.42)$ & $\mathrm{I}(.0 \mathrm{I})$ & 0.048 & 0.976 & $159(.78)$ & $45(.22)$ & 0.037 & 0.847 \\
\hline & $\mathrm{P}(94)$ & $52(.55)$ & $4 I(.44)$ & $\mathrm{I}(.0 \mathrm{I})$ & & & $145(.77)$ & $43(.23)$ & & \\
\hline \multirow[t]{2}{*}{ T3804A } & $N(101)$ & $56(.55)$ & $38(.38)$ & $7(.07)$ & 2.17 & 0.304 & $152(.74)$ & $52(.26)$ & 0.015 & 0.946 \\
\hline & $\mathrm{P}(96)$ & $49(.51)$ & $44(.46)$ & $3(.03)$ & & & $142(.74)$ & $50(.26)$ & & \\
\hline \multirow[t]{2}{*}{ G7465A } & $N(100)$ & $3 I(.31)$ & $43(.43)$ & $26(.26)$ & 0.46 & 0.793 & $105(.53)$ & $95(.48)$ & 0.439 & 0.508 \\
\hline & $P(74)$ & $25(.34)$ & $33(.45)$ & $16(.22)$ & & & $83(.56)$ & $65(.44)$ & & \\
\hline \multirow[t]{2}{*}{$\mathrm{A} / 2517 \mathrm{C}$} & $N(101)$ & $58(.57)$ & $39(.39)$ & $4(.04)$ & 0.232 & 0.890 & $155(.77)$ & $47(.23)$ & 0.207 & 0.649 \\
\hline & $P(96)$ & $58(.60)$ & $35(.37)$ & $3(.03)$ & & & $15 \mid(.79)$ & $4 \mathrm{I}(.21)$ & & \\
\hline \multirow[t]{2}{*}{ CI8626G } & $N(100)$ & $28(.28)$ & $47(.47)$ & $25(.25)$ & 1.24 & 0.538 & $103(.52)$ & $97(.49)$ & 0.392 & 0.531 \\
\hline & $P(71)$ & $25(.35)$ & $28(.39)$ & $18(.25)$ & & & $78(.55)^{\prime}$ & 64(.45) & & \\
\hline \multirow[t]{2}{*}{ A20004C } & $N(102)$ & $40(.39)$ & $45(.44)$ & $17(.17)$ & 1.726 & 0.422 & $125(.61)$ & $79(.39)$ & 1.795 & 0.18 \\
\hline & $P(89)$ & $29(.32)$ & $39(.44)$ & $21(.24)$ & & & $97(.54)$ & $81(.46)$ & & \\
\hline \multirow[t]{2}{*}{ C27224T } & $\mathrm{N}(95)$ & $31(.33)$ & $49(.52)$ & $15(.16)$ & 3.58 & 0.167 & $\mathrm{III}(.58)$ & $79(.42)$ & 2.13 & 0.144 \\
\hline & $\mathrm{P}(80)$ & $23(.29)$ & $35(.44)$ & $22(.28)$ & & & $8 \mathrm{I}(.5 \mathrm{I})$ & $79(.49)$ & & \\
\hline \multirow[t]{2}{*}{ A27237G } & $N(95)$ & $49(.52)$ & $40(.42)$ & $6(.06)$ & 0.57 & 0.751 & $138(.73)$ & $52(.27)$ & 0.677 & 0.411 \\
\hline & $P(78)$ & $37(.47)$ & $34(.44)$ & $7(.09)$ & & & $107(.69)$ & $49(.34)$ & & \\
\hline
\end{tabular}

a. $\mathrm{N}$ indicates the matched normal controls, $\mathrm{P}$ indicates the bipolar patients.

b. I represents the major allele and 2 the minor allele.

then terminated by incubation at $72^{\circ} \mathrm{C}$ for 15 minutes to inactivate the enzymes. The multiplex SBE reaction was carried out using SNP-specific primers and fluorescentlabeled terminators (the ABI PRISM SNaPshot Multiplex Kit). The short-extension reaction was performed on a thermal cycling machine for 25 cycles of $10 \mathrm{~s}$ at $96^{\circ} \mathrm{C}, 5 \mathrm{~s}$ at $50^{\circ} \mathrm{C}$, and $30 \mathrm{~s}$ at $60^{\circ} \mathrm{C}$. After short-extension, excess ddNTPs were removed from the SBE products by addition of $0.5 \mathrm{U}$ of SAP to the reaction mixture and incubation at $37^{\circ} \mathrm{C}$ for 1 hour. The purified SBE products were electrophoresed on a ABI PRISM 310 Genetic Analyzer and analyzed using GeneScan software (ABI PRISM).

\section{Statistical analysis}

The chi-squared test for allelic and genotypic distributions between patients and controls was performed using the CROSSTAB program implemented by SPSS. The HardyWeinberg equilibrium was analyzed using the HWE program, version 2.33 [37]. Pairwise LD coefficients D' [38] among the 10 SNPs were estimated and statistical significances were determined by using the SNP Alyze ${ }^{\circledast}$ program (SNP and Disease Association Analysis software; Dynacom Co., Ltd. Kanagawa, Japan). In addition, the PHASE 2.0 program $[39,40]$ was used to construct haplotypes and perform a case-control permutation test, then the Fisher's exact test was applied to test differences in haplotype frequencies between cases and controls. All Fisher's exact tests (two tails) and estimation of the odds ratio of BPD associated with a particular haplotype were performed using the PROC FREQ program implemented by SAS package (SAS Institute Inc., Cary, NC, USA). Haplotypetag SNPs were selected using SNPtagger software [41]. To consider the multiple comparisons, a Bonferroni correction was applied in this study thus the $\mathrm{p}$ value for reaching significance is 0.005 for 10 SNPs. In addition, the potential confounders such as personality disorders, substance abuses or organic disorders were not considered in the statistic analyses.

\section{Results}

Detection of TPHI gene polymorphisms in the Taiwanese Han population

To detect SNPs in the human TPH1 gene, we used the enzymatic cleavage approach to screen all 11 exons, parts of neighboring introns, and the promoter of the gene in 30 unrelated healthy and 20 BPD probands from a previously recruited population [31]. No sequence variation in the coding region of the TPH1 gene was identified. However, screening for nucleotide variants up to $-1,151$ bases in the promoter region and down to 1,572 bases in the 3'UTR identified five SNPs. Two, A-1067G (5'flankingSNP2) and G-347T (5'flankingSNP3), were found in the promoter region. Of the remaining 3 SNPs, T3804A (in1SNP1) was located in intron 1/exon 1c, while 
Table 3: Pairwise linkage disequilibrium indicated by the $D^{\prime}$ value (above the diagonal) ${ }^{a}$ and statistical significance indicated by the $p$ value (below the diagonal) ${ }^{b}$ for the ten TPHI SNPs.

\begin{tabular}{|c|c|c|c|c|c|c|c|c|c|c|}
\hline & $\mathrm{T}-1721 \mathrm{G}$ & A-I067G & G-347T & T3840A & G7465A & $\mathrm{Al} 25 \mathrm{I} 7 \mathrm{C}$ & CI8626G & A20004C & $\mathrm{C} 27224 \mathrm{~T}$ & A27237G \\
\hline $\mathrm{T}-|72| \mathrm{G}$ & & 1.000 & 0.911 & 0.129 & 0.834 & 0.505 & 0.601 & 0.726 & 0.329 & 0.177 \\
\hline A- $1067 \mathrm{G}$ & $<0.001$ & & 0.913 & 0.076 & 0.863 & 0.537 & 0.655 & 0.722 & 0.391 & 0.274 \\
\hline G-347T & $<0.001$ & $<0.001$ & & 0.121 & 0.840 & 0.450 & 0.645 & 0.655 & 0.447 & 0.032 \\
\hline T3840A & 0.020 & 0.166 & 0.033 & & 0.969 & 0.575 & 0.870 & 0.652 & 0.512 & 0.574 \\
\hline G7465A & $<0.001$ & $<0.001$ & $<0.001$ & $<0.001$ & & 0.685 & 0.711 & 0.826 & 0.741 & 0.929 \\
\hline $\mathrm{A} 12517 \mathrm{C}$ & $<0.001$ & $<0.001$ & $<0.001$ & $<0.001$ & $<0.001$ & & 0.684 & 0.320 & 0.663 & 0.039 \\
\hline Cl8626G & $<0.001$ & $<0.001$ & $<0.001$ & $<0.001$ & $<0.001$ & $<0.001$ & & 0.765 & 0.684 & 0.780 \\
\hline $\mathrm{A} 20004 \mathrm{C}$ & $<0.001$ & $<0.001$ & $<0.001$ & $<0.001$ & $<0.001$ & $<0.001$ & $<0.001$ & & 0.624 & 0.625 \\
\hline C27224T & $<0.001$ & $<0.001$ & $<0.001$ & $<0.001$ & $<0.001$ & $<0.001$ & $<0.001$ & $<0.001$ & & 0.956 \\
\hline A27237G & 0.203 & 0.096 & 0.840 & $<0.001$ & $<0.001$ & 0.809 & $<0.001$ & $<0.001$ & $<0.001$ & \\
\hline
\end{tabular}

a Standardized linkage disequlibrium coefficient (absolute D' value) of Lewontin was shown.

b Significant levels based on the chi-squared distribution to test whether the disequilibrium value differs from zero (one degree of freedom). Bold and underline indicate no significant LD at the $p<0.05$ level.

Table 4: Haplotype frequency estimation and test statistics between case and control.

\begin{tabular}{|c|c|c|c|c|c|}
\hline Haplotype $^{a}$ & Patient & Normal & Fisher's Exact Test ( $P$ value $)^{b}$ & $\mathbf{O R}^{\mathrm{b}, \mathrm{c}, \mathrm{d}}$ & $95 \% \mathrm{Cld}^{\mathrm{d}}$ \\
\hline TAGTAAGACA & 0.340 & 0.359 & 0.755 & 0.919 & $0.61-1.38$ \\
\hline TAGAGACCTG & 0.145 & 0.140 & 1.000 & 1.035 & $0.59-1.80$ \\
\hline GGTTGCCCTA & 0.095 & 0.068 & 0.366 & 1.439 & $0.70-2.96$ \\
\hline TAGTAACACA & 0.010 & 0.039 & 0.105 & 0.250 & $0.05-1.19$ \\
\hline TAGTAAGATA & 0.025 & 0.010 & 0.278 & 2.615 & $0.50-13.64$ \\
\hline TAGTGCGACA & 0.025 & 0.015 & 0.498 & 1.735 & $0.41-7.36$ \\
\hline GGGAGACCCA & 0.025 & 0 & 0.028 & -- & -- \\
\hline TAGTAACCTG & 0.020 & 0 & 0.058 & -- & -- \\
\hline TAGTGACCTG & 0.020 & 0.010 & 0.443 & 2.081 & $0.38-11.49$ \\
\hline TAGAGACATG & 0.020 & 0.019 & 1.000 & 1.031 & $0.25-4.18$ \\
\hline GGTTGCCCTG & 0.020 & 0.010 & 0.443 & 2.082 & $0.38-11.49$ \\
\hline GGTAGACCCA & 0.015 & 0.024 & 0.724 & 0.612 & $0.14-2.59$ \\
\hline Others & 0.240 & 0.306 & 0.149 & 0.717 & $0.46-1.11$ \\
\hline Total & & & 0.082 & & \\
\hline$P$ value of permutation test & 0.602 & & & & \\
\hline
\end{tabular}

a. The order of the markers, shown $5^{\prime} \rightarrow 3^{\prime}$, is (left to right) T-I72IG, A-1067G, G-347T, T3804A, G7465A, AI25I7C, CI8626G, A20004C, C27224T, A27237G.

b. Chi-square, Fisher's Exact Test and Odds Ratio were calculated by using the SAS program.

c. The Odds Ratio could not be calculated for the haplotype GGGAGACCCA and TAGTAACCTG, because of the zero value in the population.

d. OR: odds Ratio; Cl: confidence Interval.

C27224T (3'UTRSNP1) and A27237G (3'UTRSNP2) were located in the 3'UTR of exon 11.

\section{SNP genotyping and single locus association analysis}

For further association analysis, all 5 SNPs identified in this study, plus one polymorphism in the promoter region (5'flankingSNP1;[33]) and four selected from the dbSNP database (in2SNP1, in3SNP1, in6SNP1, and in7SNP1), were genotyped with MSBE or ARMS (Table 1). All genotypes were in Hardy-Weinberg equilibrium (HWE), except for the G-347 T marker in the promoter region that had departure from the HWE in both controls $(\mathrm{p}=0.024)$ and patients $(\mathrm{p}=0.024)$. Genotype coverage was generally good and about $90 \%$ of the subjects were successfully typed.

All 10 SNPs were genotyped and have been analyzed by Fisher's exact test between the case and control groups. No association can be obtained between any of the TPH1 gene polymorphisms and BPD. The genotypic and allelic distributions of each marker are listed in Table 2. 
Table 5: Haplotype frequency and test statistics between cases and controls using htSNPs.

\begin{tabular}{|c|c|c|c|c|c|c|}
\hline $\begin{array}{l}\text { Haplotypes } \\
\text { from htSNPsa }\end{array}$ & $\begin{array}{l}\text { Represented haplotypes } \\
\text { from I0 SNPsa }\end{array}$ & Patient (frequency) & Normal & $\begin{array}{l}\text { Fisher's Exact Test } \\
(P \text { value })^{b}\end{array}$ & OR $^{\mathrm{a}, \mathrm{c}}$ & $95 \% \mathrm{Clc}$ \\
\hline TAG & $\begin{array}{l}\text { TAGTAAGACA } \\
\text { TAGTAAGATA }\end{array}$ & 0.365 & 0.369 & 1.000 & 0.983 & $0.66-1.47$ \\
\hline TGC & $\begin{array}{l}\text { TAGAGACCTG } \\
\text { TAGTGACCTG } \\
\text { TAGTGACATG }\end{array}$ & 0.185 & 0.169 & 0.699 & 1.109 & $0.66-1.85$ \\
\hline GGC & $\begin{array}{l}\text { GGTTGCCCTA } \\
\text { GGGAGACCCA } \\
\text { GGTTGCCCTG } \\
\text { GGTAGACCCA }\end{array}$ & 0.155 & 0.102 & 0.137 & 1.616 & $0.89-2.92$ \\
\hline TAC & $\begin{array}{l}\text { TAGTAACACA } \\
\text { TAGTAACCTG }\end{array}$ & 0.030 & 0.039 & 0.787 & 0.765 & $0.26-2.25$ \\
\hline TGG & TAGCGCGACA & 0.025 & 0.015 & 0.498 & 1.735 & $0.4 I-7.36$ \\
\hline Others & & 0.240 & 0.306 & 0.149 & 0.717 & $0.46-1.11$ \\
\hline Total & & & & 0.446 & & \\
\hline
\end{tabular}

a. SNPs in bold and dark color are htSNPs selected from common haplotypes using the SNPtagger program.

b. Chi-square, Fisher's Exact Test and Odds Ratio were calculated by using the SAS program.

c. OR: odds Ratio; Cl: confidence Interval.

\section{Pairwise linkage disequilibrium (LD) measurement and haplotype analyses}

The size of the human TPH1 gene is about $29 \mathrm{~kb}$ and the LD between all pairs of 10 SNP markers in all subjects was estimated using the SNP Alyze ${ }^{\circledast}$ program (Table 3 ). The data above and below the diagonal line in Table 3 show, respectively, the results of the pairwise LD analysis, as indicated by the D' [38]; a higher value indicating a higher degree of LD), and the p value for the chi-squared test. As shown in Table 3, the D' values ranges from 0.032 to 1 and the majority of the $\mathrm{D}^{\prime}$ value is greater than 0.5 . These data suggested that sequence variants within the TPH1 gene are in strong disequilibrium (the upper diagonal of the Table 3). Furthermore, as indicated by the lower diagonal of Table 3, statistically significant LD was detected for almost all marker pairs among these SNPs. Few exceptions were observed for marker pairs T3840A / A-1067G, A27237 / G-347T, and A27237 / GA12517C in which the $D^{\prime}$ values are 0.076, 0.032, and 0.039, respectively.

Haplotypes constructed using the PHASE 2.0 program [39] revealed a total of 70 haplotypes in combined controls and patients (data not shown). Among these haplotypes, the majority is in very low frequency but the four major haplotypes with frequency greater than $2 \%$ are found in $59.8 \%$ of the total population. Estimation of haplotype distribution and the Fisher's exact test values for testing the significance of differences in individual haplotype frequencies between case and control groups for the haplotypes with frequency $>2 \%$ in at least one group were listed in Table 4 . Additional test was performed to assess overall haplotype frequency profile dif- ferences, rather than frequency differences for a specific haplotype, and p value estimated from 1000 permutation tests was also obtained (Table 4). Although a trend of significance was detected for the GGGAGACCCA haplotype between the case and control groups $(p=0.028)$ and few haplotypes showed slightly increased risks in which the value of odds ratios are larger than 2 , the significances were abolished after Bonferroni correction for multiple tests thus suggested the effect is minor (Table 4). Furthermore, the overall comparison for all haplotypes between two groups was not significant $(\mathrm{p}=0.082)$ and the $\mathrm{p}$ value from 1000 time permutation test was also not significant $(\mathrm{p}=0.602)$.

\section{Haplotype tag selection}

Selecting haplotype-tag SNPs (ht-SNPs) can systematically and efficiently refine the process of haplotype construction and reduce the marker number for genotyping. In this study, three htSNPs (5'flankingSNP1, in2SNP1, in6SNP1) were selected to represent all haplotypes with frequencies larger than $2 \%$ using SNPtagger software [41] (Table 5). Results from the htSNP analysis suggest that the information obtained by examining three SNPs (instead of 10) should be sufficient for genetic analysis, since these can be used to construct and represent all common haplotypes with frequency $>2 \%$. Five haplotypes were constructed using these $3 \mathrm{htSNPs}$ and statistical analyses detected no differences in haplotype distributions between cases and controls (Table 5).

\section{Discussion}

The involvement of the TPH1 gene in the pathogenesis of affective disorder is supported by several lines of evidence. 
Previous studies have reported a significant association between TPH1 intron 7 A218C polymorphism and BPD in the French population [21]. In addition, two current meta-analyses confirmed the significant association of suicide-related behavior with TPH1 A218 polymorphism $[42,43]$ and suggested that the A allele has a dose-dependent effect on the risk of suicidal behavior [43]. Since these results suggested that TPH1 could be a strong candidate for involvement in BPD, we have systematically searched all the exons and promoter region of the gene for SNPs. Five polymorphisms were identified, one of which, 3'UTRSNP2, is a novel polymorphism not previously reported. The only sequence variant found in all TPH1 exons was in the exon 1c/intron 1 region (T3804A, dbSNP ID: rs623580), but the polymorphism is within the 5'UTR and therefore does not result in an amino acid substitution. This finding is consistent with a previous report in which no coding sequence variant of TPH1 was detected in Americans (Indians or Caucasians), Italians, and Finns [44]. These results demonstrate the highly conserved nature of the human TPH1 gene. The exon 1c/ intron 1 T3804A polymorphism has been previously reported and has an estimated minor allele frequency of 0.001 in the Swiss population $[34,45]$.

The five identified SNPs, together with five additional SNPs taken from the literature and a public database, were tested for an association with BPD in Taiwanese patients. In general, the alleles in the TPH1 gene were common, with minor allele frequencies ranging from $21 \%$ to $49 \%$ and from $22 \%$ to $49 \%$ in cases and controls, respectively. The genotypic frequencies of all markers, except the G347T (5'flankingSNP3) marker in the promoter region, showed Hardy-Weinberg equilibrium (HWE) in both populations. The departure from HWE of 5 'flankingSNP3 was observed in both controls $(\mathrm{p}=0.024)$ and patients ( $\mathrm{p}$ $=0.024)$. A separate study in our lab indicated that the location of the G-347T polymorphism is on the transcriptional repressor GATA1 binding site [46] and alteration of alleles indeed change promoter activity in a luciferase reporter gene system [47]. The departure from HWE could be explained by the negative selection of the homozygous TT individuals. And the presence of very low frequency of TT genotype in the population may be the reason for the impossibility of detecting any association. Despite the strong functional role of the TPH1 G-347T polymorphism, no association was detected between any of the polymorphisms and BPD in Taiwanese.

The extent and distribution of LD in humans has been a hot topic, especially for gene mapping of complex diseases. In this study, significant $\mathrm{LD}$, as measured by the $\mathrm{D}^{\prime}$ and $\mathrm{P}$ values using the SNP Alyze ${ }^{\circledast}$ program, could be detected between T-1721G and C27224T polymorphisms of the TPH1 gene, which are separated by roughly $29 \mathrm{~kb}$
(Table 3). Because LD-induced association between multiple loci that harbor disease-predisposing alleles can be identified by haplotype-based analyses [48], haplotypes were constructed and their frequencies were compared between cases and controls. Haplotype distributions among 10 TPH1 SNPs were estimated and twelve haplotypes with frequency larger than $2 \%$ in at least one group were listed (Table 4). The three most common haplotypes were identical in both groups and were found in $58 \%$ and $56.7 \%$ of the patients and controls, respectively. Although significant difference in haplotype distribution was seen in one comparison, the association was weak and was lost after the Bonferroni correction for multiple tests. Additional permutation tests for haplotype distributions in case and control groups were performed and result indicated no differences in haplotype profile between two groups ( $p$ value $=0.602)$. The data suggest that both BPD patients and controls are actually from the same population thus it implies the TPH1 gene may not be related to BPD etiologies.

Positive association between TPH1 intron 7 polymorphism and BPD was identified in our previous study [31], but the replication with extended samples has failed to confirm this association in both single-locus and haplotype analyses. One possible reason for this discrepancy could be at the sampling bias as the age of controls in the extended population is much younger than the cases. Since mood disorders may occur late in life, the sampling bias represents a major limitation of this study. Another possible explanation may be that the TPH1 gene has only a minor effect on BPD etiology, this effect being missed when heterogeneous samples are used. Alternatively, the positive association we obtained initially could be a false positive outcome from a very small sample size being used. Recently, studies of Tph1 (the original Tph) knockout mice were found to express normal amounts of serotonin in brain, but not in the periphery [11], and resulted in a cardiac dysfunction phenotype [49]. Follow up studies found that the second tryptophan hydroxylase (TPH2, also known as nTPH) gene is predominantly expressed in the brain stem, while the classical TPH1 is expressed in the pineal gland [14] and peripheral tissues (duodenum, kidney or lung; [15]. The amount of TPH2 mRNA expression in individual raphe cells was estimated to be approximately 2.5-fold greater than the level of TPH1 expression in pinealocytes [14]. These findings have changed the consideration of linking polymorphism of TPH1 gene with various psychiatric diseases [12] and perhaps, could explain the lack of association between the TPH1 gene and BPD obtained in this study. Whether these two paralog proteins are regulated independently or if they have distinct functions in the brain are still under investigation; studies to establish connections between TPH2 gene and various psychiatric diseases including BPD are on going 
and should provide more insights regarding the TPH2 function in the brain.

Studies on sequence variations in the human genome have revealed that the human genome can be parsed objectively into haplotype blocks, with limited diversity within each block [50,51]. Johnson et al. [52] determined the extended haplotype at any given locus in a population to identify the SNPs in a gene or a LD region, information that is essential for association studies. The so-called "haplotype tag SNPs (htSNPs)" capture the majority of haplotype diversity within a region and thus represent the minimal number of markers that need to be typed to define the common haplotypes (higher than 5\% frequency in the population). In this study, we used a publicly program to define htSNPs that represent all haplotypes of the TPH1 locus with a frequency $>2 \%$ [41]. Three htSNPs, corresponding to all common haplotypes were generated using SNPtagger software [53] (Table 5). Although further analysis using haplotypes constructed with htSNPs revealed no differences in frequency distributions between cases and controls (Table 5), the htSNPs selected for human TPH1 gene significantly reduce the number of markers required for genotype analysis (in this case from 10 to 3 SNPs), which may be useful in other studies on the Taiwanese Han population.

\section{Conclusion}

Bipolar disorder is a complex genetic disorder with a spectrum of phenotype is associated with bipolar susceptibility genes. Since the subject assessment in this study was only by direct clinical interview according to the DSM-IV but not supported by any other standard tools like the SCID, it is worth noting the potential weakness of the study. The simple assessment procedure without dimensional measures of other psychopathological features also limits the possibility to detect association with particular attribute related to the disease. In summary, results from both single-locus and haplotype analyses did not support the role of TPH1 gene in BPD etiology. Furthermore, our data indicated significant LD within this $29 \mathrm{~Kb}$ interval of the TPH1 gene in Taiwanese population. Since haplotype frequencies and $\mathrm{LD}$ often differ between racial/ethnic groups, the three htSNPs identified in this study should be beneficial in future application for genetic study in Taiwanese population.

\section{Competing interests}

The author(s) declare that they have no competing interests.

\section{Authors' contributions}

TJL was in charge of clinical examination and provided clinical samples. CYW designed polymorphism screening methods and identified all TPH1 polymorphisms in Tai- wanese. HWT conducted genotyping experiments and provided statistical analysis. YJL contributed to genotyping data analysis. HSS provided overall study design, analysis, and drafted the manuscript. All authors read and approved the final manuscript.

\section{Acknowledgements}

This study was supported by grants from the National Science Council, Taiwan, ROC (NSC 89-2320-B-006-062-A89-089 and NSC 90-2320-B-006073).

\section{References}

I. Yeh EKHHGTY: Mental disorder in Taiwan : Epidemiological studies of community population. In Chinese Societies and Mental Health Edited by: Lin TY, Lin TY and Yeh EK. Hong Kong, Oxford University Press; 1994.

2. Craddock N, Jones I: Genetics of bipolar disorder. J Med Genet 1999, 36:585-594.

3. Comings DE: Candidate genes and association studies in psychiatry. Am J Med Genet 1994, 54:324-325.

4. Risch N, Merikangas K: The future of genetic studies of complex human disease. Science 1996, 273:1516-1517.

5. Craddock N, Dave S, Greening J: Association studies of bipolar disorder. Bipolar Disorders 2001, 3:284-298.

6. Hoyer D, Lubbert H, Bruns C: Molecular pharmacology of somatostatin receptors. Naunyn Schmiedebergs Arch Pharmacol 1994, 350:44I-453.

7. Van Praag HM: 5-HT-related, anxiety- and/or aggressiondriven depression. Int Clin Psychopharmacol 1994, 9 Suppl I:5-6.

8. Bellivier F, Henry C, Szoke A, Schurhoff F, Nosten-Bertrand M, Feingold J, Launay JM, Leboyer M, Lapianche JL: Serotonin transporter gene polymorphisms in patients with unipolar or bipolar depression. Neuroscience Letters 1998, 255:|43-|46.

9. Brunner HG, Nelen M, Breakefield XO, Ropers HH, van Oost BA: Abnormal behavior associated with a point mutation in the structural gene for monoamine oxidase A. Science 1993, 262:578-580.

10. Jequier E, Robinson DS, Lovenberg W, Sjoerdsma A: Further studies on tryptophan hydroxylase in rat brainstem and beef pineal. Biochem Pharmacol 1969, I8:1071-108I.

II. Veenstra-VanderWeele J, Cook EHJ: Knockout mouse points to second form of tryptophan hydroxylase. Mol Intervent 2003, 3:72-75.

12. Walther DJ, Peter JU, Bashammakh S, Hortnagl H, Voits M, Fink H, Bader M: Synthesis of serotonin by a second tryptophan hydroxylase isoform. Science 2003, 299:76.

13. Craig SP, Boularand S, Darmon MC, Mallet J, Craig IW: Localization of human tryptophan hydroxylase (TPH) to chromosome I Ip I5.3----p|4 by in situ hybridization. Cytogenet Cell Genet 1991, 56:157-159.

14. Patel PD, Pontrello C, Burke S: Robust and tissue-specific expression of $\mathrm{TPH} 2$ versus $\mathrm{TPHI}$ in rat raphe and pineal gland. Biol Psychiatry 2004, 55:428-433.

15. Walther DJ, Bader M: A unique central tryptophan hydroxylase isoform. Biochem Pharmacol 2003, 66:1673-1680.

16. Molliver ME: Serotonergic neuronal systems: what their anatomic organization tells us about function. J Clin Psychopharmacol 1987, 7:3S-23S.

17. Peters EJ, Slager SL, McGrath PJ, Knowles JA, Hamilton SP: Investigation of serotonin-related genes in antidepressant response. Mol Psychiatry 2004, 9:879-889.

18. Zill P, Baghai TC, Zwanzger P, Schule C, Eser D, Rupprecht R, Moller $\mathrm{HJ}$, Bondy B, Ackenheil M: SNP and haplotype analysis of a novel tryptophan hydroxylase isoform (TPH2) gene provide evidence for association with major depression. Mol Psychiatry 2004, 9: 1030-1036.

19. Boularand S, Darmon MC, Mallet J: The human tryptophan hydroxylase gene. An unusual splicing complexity in the 5'untranslated region. J Biol Chem 1995, 270:3748-3756.

20. Wang GA, Coon SL, Kaufman S: Alternative splicing at the 3'cDNA of human tryptophan hydroxylase. J Neurochem 1998 , 7|:1769-1772. 
21. Bellivier F, Leboyer M, Courtet P, Buresi C, Beaufils B, Samolyk D, Alliaire J, Feingold J, Mallet J, Malafosse A: Association between the tryptophan hydroxylase gene and manic-depressive illness. Arch Gen Psychiatry 1998, 55:33-37.

22. Nielsen DA, Virkkunen M, Lappalainen J, Eggert M, Brown GL, Long JC, Goldman D, Linnoila M: A tryptophan hydroxylase gene marker for suicidality and alcoholism. Arch Gen Psychiatry 1998, 55:593-602.

23. Manuck SB, Flory JD, Ferrell RE, Dent KM, Mann JJ, Muldoon MF: Aggression and anger-related traits associated with a polymorphism of the tryptophan hydroxylase gene. Biol Psychiatry 1999, 45:603-614.

24. Nielsen DA, Goldman D, Virkkunen M, Tokola R, Rawlings R, Linnoila $M$ : Suicidality and 5-hydroxyindoleacetic acid concentration associated with a tryptophan hydroxylase polymorphism. Arch Gen Psychiatry 1994, 5 I:34-38.

25. Jonsson EG, Goldman D, Spurlock G, Gustavsson JP, Nielsen DA, Linnoila M, Owen MJ, Sedvall GC: Tryptophan hydroxylase and catechol-O-methyltransferase gene polymorphisms: relationships to monoamine metabolite concentrations in CSF of healthy volunteers. Eur Arch Psychiatry Clin Neurosci 1997, 247:297-302.

26. Lalovic A, Turecki G: Meta-analysis of the association between tryptophan hydroxylase and suicidal behavior. Am J Med Genet 2002, II 4:533-540.

27. Serretti A, Cristina S, Lilli R, Cusin C, Lattuada E, Lorenzi C, Corradi B, Grieco G, Costa A, Santorelli F, Barale F, Nappi G, Smeraldi E: Family-based association study of 5-HTTLPR, TPH, MAO-A, and DRD4 polymorphisms in mood disorders. Am J Med Genet 2002, II 4:36I-369.

28. Tang G, Ren D, Xin R, Qian Y, Wang D, jiang S: Lack of association between the tryptophan hydroxylase gene A218C polymorphism and attention-deficit hyperactivity disorder in Chinese Han population. Am J Med Genet 200I, 105:485-488.

29. Chotai J, Serretti A, Lorenzi C: Interaction between the Tryptophan Hydroxylase Gene and the Serotonin Transporter Gene in Schizophrenia but Not in Bipolar or Unipolar Affective Disorders. Neuropsychobiology 2004, 5 I:3-9.

30. Lai TJ, Wu CY, Fann CSJ, Chang FM, S. SH: Association study of the tryptophan hydroxylase gene polymorphism and bipolar affective disorder in Taiwan. Journal of Genetics and Molecular Biology (Taiwan) 2002, 13:101-104.

31. Kim SW, Park SY, Hwang O: Up-regulation of tryptophan hydroxylase expression and serotonin synthesis by sertraline. Mol Pharmacol 2002, 6I:778-785.

32. Kim SW, Park SY, Hurang O: AUp-regulation of tryptophan hydroxylase expression and serotonin synthesis by sertraline. Mol Pharmacol 2002, 6I:778-785.

33. Paoloni-Giacobino A, Mouthon D, Lambercy C, Vessaz M, Coutant_Zimmerli S, Rudolph W, Malafosse A, Buresi C: Identification and analysis of new sequence variants in the human tryptophan hydroxylase (TPH) gene. Molecular Psychiatry 2000, 5:49-55.

34. dbSNP: http://www.ncbi.nlm.nih.gov/projects/SNPI.

35. Primer3: http://www-genome.wi.mit.edu/cgi-bin/primerl primer3 www.cgi.

36. Ott J: Analysis of human genetic linkage. 3rd edition edition. Baltimore, Johns Hopkins University Press; 1999.

37. Lewontin RC: On measures of gametic disequilibrium. Genetics 1988, I 20:849-852.

38. Stephens M, Smith NJ, Donnelly P: A new statistical method for haplotype reconstruction from population data. Am J Hum Genet 200I, 68:978-989.

39. Stephens M, Donnelly P: A comparison of bayesian methods for haplotype reconstruction from population genotype data. Am J Hum Genet 2003, 73: I162-1169.

40. Ke X, Cardon LR: Efficient selective screening of haplotype tag SNPs. In press. Bionifomatics 2002.

41. Rujescu D, Giegling I, Sato T, Hartmann AM, Moller HJ: Genetic variations in tryptophan hydroxylase in suicidal behavior: analysis and meta-analysis. Biol Psychiatry 2003, 54:465-473.

42. Bellivier F, Chaste P, Malafosse A: Association between the TPH gene A2 I8C polymorphism and suicidal behavior: a metaanalysis. Am J Med Genet 2004, I 24B:87-9I.

43. Han L, Nielsen DA, Rosenthal NE, Jefferson K, Kaye W, Murphy D, Altemus M, Humphries J, Cassano G, Rotondo A, Virkkunen M, Lin- noila M, Goldman D: No coding variant of the tryptophan hydroxylase gene detected in seasonal affective disorder, obsessive-compulsive disorder, anorexia nervosa, and alcoholism. Biol Psychiatry 1999, 45:6|5-619.

44. Rotondo A, Schuebel K, Bergen A, Aragon R, Virkkunen M, Linnoila $M$, Goldman D, Nielsen D: Identification of four variants in the tryptophan hydroxylase promoter and association to behavior. Mol Psychiatry 1999, 4:360-368.

45. Raich N, Clegg CH, Grofti J, Romeo PH, Stamatoyannopoulos G: GATAI and YYI are developmental repressors of the human epsilon-globin gene. Embo J 1995, 14:80 I-809.

46. Sun HS, Fann CSJ, Lane HY, Chang YT, Chang CJ, Liu YL, Cheng ATA A functional polymorphism in the promoter region of the tryptophan hydroxylase (TPHI) gene is associated with alcohol dependence in one aboriginal group in Taiwan. Alcoholism - Clinical and Experimental Research 2005, 29: I-7.

47. Fallin D, Cohen A, Essioux L, Chumakov I, Blumenfeld M, Cohen D, Schork NJ: Genetic analysis of case/control data using estimated haplotype frequencies: application to APOE locus variation and Alzheimer's disease. Genome Res 200I, II:|43-|5|.

48. Cote F, Thevenot E, Fligny C, Fromes Y, Darmon M, Ripoche MA, Bayard E, Hanoun N, Saurini F, Lechat P, Dandolo L, Hamon M, Mallet J, Vodjdani G: Disruption of the nonneuronal tph I gene demonstrates the importance of peripheral serotonin in cardiac function. Proc Natl Acad Sci U S A 2003, I00:13525-30. Epub 2003 Nov 3 ..

49. Gabriel SB, Schaffner SF, Nguyen H, Moore JM, Roy J, Blumenstiel B, Higgins J, DeFelice M, Lochner A, Faggart M, Liu-Cordero SN, Rotimi C, Adeyemo A, Cooper R, Ward R, Lander ES, Daly MJ, Altshuler D: The structure of haplotype blocks in the human genome. Science 2002, 296:2225-2229.

50. Stumpf MP: Haplotype diversity and the block structure of linkage disequilibrium. Trends Genet 2002, 18:226-228.

5I. Johnson GC, Esposito L, Barratt BJ, Smith AN, Heward J, Di Genova G, Ueda H, Cordell HJ, Eaves IA, Dudbridge F, Twells RC, Payne F, Hughes W, Nutland S, Stevens H, Carr P, Tuomilehto-Wolf E, Tuomilehto J, Gough SC, Clayton DG, Todd JA: Haplotype tagging for the identification of common disease genes. Nat Genet 200I, 29:233-237.

52. SNPtagger: http://www.well.ox.ac.uk/ xiayi/haplotype/.

\section{Pre-publication history}

The pre-publication history for this paper can be accessed here:

\section{http://www.biomedcentral.com/1471-2350/6/14/prepub}

Publish with Bio Med Central and every scientist can read your work free of charge

"BioMed Central will be the most significant development for disseminating the results of biomedical research in our lifetime. "

Sir Paul Nurse, Cancer Research UK

Your research papers will be:

- available free of charge to the entire biomedical community

- peer reviewed and published immediately upon acceptance

- cited in PubMed and archived on PubMed Central

- yours - you keep the copyright
BioMedcentral 